\title{
Psicologia, Povos e Comunidades Tradicionais e Diversidade Etnocultural
}

\section{Psychology, People and Traditional Communities and Ethnocultural Diversity Psicología, Pueblos y Comunidades Tradicionales y Diversidad Etnocultural}

\author{
Adolfo Pizzinato ${ }^{1}$ \\ ${ }^{1}$ Universidade Federal do Rio Grande do Sul, RS, Brasil. \\ Danilo Silva Guimarães ${ }^{2}$ \\ Jáder Ferreira Leite ${ }^{3}$ \\ ${ }^{3}$ Universidade Federal do Rio Grande do Norte, RN, Brasil.
}

O atual momento histórico e político do país demanda diversos posicionamentos da Psicologia brasileira, de resistência e enfrentamento, através dos fazeres de psicólogas e psicólogos, face aos ataques e ameaças que os povos tradicionais têm sofrido, nas mais diversas partes geográficas e nos mais diferentes campos de atuação. Os povos e comunidades tradicionais aqui destacados dizem respeito a grupos culturalmente diferenciados em relação à sociedade nacional dominante, que se reconhecem como tais, que possuem formas próprias de organização social, que ocupam e usam territórios e recursos naturais como condição para sua reprodução cultural, social, religiosa, ancestral e econômica, utilizando conhecimentos, inovações e práticas gerados e transmitidos, predominantemente, por tradição oral. Entre os povos e comunidades tradicionais do Brasil estão quilombolas, ciganos, matriz africana, seringueiros, castanheiros, pescadores artesanais, marisqueiras, ribeirinhos, caiçaras, praieiros, sertanejos, jangadeiros, açorianos, campeiros, varzanteiros, pantaneiros, caatingueiros, e minorias étnicas como grupos de imigrantes e comunidades de diáspora entre outros.

Nunca antes a Psicologia brasileira se deparou com discursos tão explícitos de ódio e de ameaça aos direitos das comunidades tradicionais como vivemos no atual momento. Entretanto, isso não significa que a Psicologia tenha se despertado para a necessidade de ação direta em defesa dos povos tradicionais apenas no último ano. Ao contrário, a Psicologia brasileira, através de práticas de seus profissionais e do posicionamento institucional enquanto categoria profissional, há muito se alinha a movimentos teórico-epistemológicos consoantes com a mesma preocupação em outros países, além de se somar às reivindicações de diferentes movimentos sociais vinculados a tais comunidades.

Um dos marcos da entrada da Psicologia, enquanto classe profissional, no campo da atenção psicossocial às comunidades indígenas remonta a uma deliberação do $4^{\circ}$ Congresso Nacional de Psicologia, de 2001, que recomendou ao Conselho Federal de Psicologia (CFP) uma abordagem estruturada aos povos indígenas. Seguindo essa deliberação, no ano de 2004, o CFP realizou uma parceria com o Conselho Indigenista Missionário (CIMI), organização católica que afirma ter o propósito de fortalecer o processo de incremento da autonomia dos povos indígenas através da construção de um projeto alternativo, multiétnico, popular e democrático. Essa parceria visou a realização do Seminário Nacional Subjetividade e Povos Indígenas em novembro de 2004, que teve a colaboração de 50 líderes comunitários de diferentes partes do Brasil (CRPSP, 2010). Um dos resultados desse seminário foi a criação, em 2008, do Grupo de Trabalho Psicologia e Povos Indígenas, no âmbito do Conselho Regional de Psicologia da $6^{\text {a }}$ Região (CRPSP) que produziu importantes referências para a categoria profissional (CRPSP, 2010; 2016). 
Outro marco relativo a esse posicionamento deu-se com a realização do "Seminário Nacional A questão da terra: desafios para a Psicologia", no ano de 2006, organizado pelo CFP (2006). Na ocasião, um conjunto de discussões se deu no sentido de aproximar a Psicologia dos modos de vida de pessoas e coletivos que organizam sua existência numa relação fundamental com a terra, as florestas e os recursos naturais, permitindo visibilizar um contingente populacional marcado por desigualdades históricas no acesso à terra, por ameaças constantes de perda de seus territórios (povos indígenas, comunidades quilombolas, trabalhadores e trabalhadoras rurais sem terra, movimentos de atingidos por grandes empreendimentos, tais como barragens, mineradoras etc., quebradeiras de coco) e pela forte presença de um patrimônio histórico-cultural que atravessa a constituição identitária de nosso país.

Uma iniciativa, voltada mais especificamente para a orientação do trabalho de psicólogos e psicólogas nos diversos contextos que se articulam com a questão da terra, foi a elaboração das "Referências Técnicas para Atuação das(os) psicólogas(os) em Questões Relativas a Terra”, publicada no ano de 2013 (CFP). Tal iniciativa foi pensada no âmbito das ações do Centro de Referência Técnica em Psicologia e Políticas Públicas (Crepop) que, dentre suas funções, visa fomentar e qualificar a participação da Psicologia no campo das políticas públicas. Nesse material foram tratadas questões relativas às possibilidades de atuação da Psicologia nas políticas voltadas para os contextos rurais, especialmente aqueles voltados para a agricultura familiar, segmento historicamente marcado pela resistência e por lutas constantes na defesa de sua existência.

Destacamos, ainda, que psicologias indígenas têm se diversificado mundialmente e ganhado visibilidade no campo de dispersão característico do cenário contemporâneo da Psicologia como ciência e profissão. Os projetos de Psicologia indígena são múltiplos e dizem respeito às especificidades étnico-culturais de cada povo, que estabelece parâmetros para um diálogo com o campo geral da Psicologia enquanto ciência, ao mesmo tempo em que resiste a concepções e práticas colonialistas imbricados em projetos clássicos de Psicologia ( Groot, Hodgetts, Nikora, \& Leggat-Cook, 2011; Hwang, 2017; Li, Hod- getts,\& Foo, 2019; Guimarães, no preloํ). A resistência que as psicologias indígenas buscam promover no cenário internacional reconhece que a atuação do psicólogo deriva de concepções e práticas enraizados nas tradições greco-romanas e judaico-cristãs, constitutivas ciências modernas. As psicologias indígenas demandam o reconhecimento das matrizes étnico-culturais que estão na base das teorias e abordagens psicológicas, ao mesmo tempo em que uma reflexão sobre a (in)adequação dessas teorias e abordagens em cenários étnico-culturais distintos, como o das comunidades tradicionais referidas nesse número especial. Trata-se, portanto de poder identificar e enfrentar possíveis e irrefletidos resquícios de violência epistêmica (Teo, 2011) presentes nos saberes acadêmicos consolidados, rumo a possibilidades de construção de novidades em diálogo com os saberes e práticas das comunidades envolvidas, detentoras de conhecimentos ancestrais relevantes à prática da psicóloga e do psicólogo.

As demandas para atuação do psicólogo junto a comunidades tradicionais, por sua vez, também se ampliam, na medida em que tais comunidades se vêm atravessadas pela circulação de mercadorias, informações e pessoas das sociedades nacionais que se difundiram mundialmente. Junto com essa circulação, vemos ampliadas demandas por políticas públicas de saúde, educação e a reivindicação por direitos humanos básicos, em relação às quais a Psicologia articula conhecimentos fundamentais que podem contribuir em um cenário de complexas tentativas de diálogo. Cabe aos psicólogos, portanto, compreender as especificidades desses contextos, as possibilidades e limites das psicologias, em sua diversidade, produzirem caminhos colaborativos de construção de conhecimento e atuação profissional.

Assim, atendendo a uma demanda política da categoria, a Revista Psicologia: Ciência e Profissão organizou essa edição especial, com um edital de chamada pública de artigos específicos desse campo de produção acadêmica e exercício profissional. Os artigos selecionados discutem práticas e saberes da Psicologia articulados às comunidades e povos tradicionais da sociedade brasileira. Os textos desta edição têm como eixo de discussão os avanços teórico-metodológicos do campo, pesquisas e relatos de práticas diretamente implicadas com o combate às iniqui-

${ }^{1}$ Guimarães, D. S. (no prelo). Dialogical multiplication: Principles for an indigenous psychology. Suíça: Springer. 
dades, à exclusão social, práticas de apagamento e extermínio e/ou a promoção da cidadania e direitos sociais destes coletivos, ou a visibilização de formas de organização social, estratégias de resistência nos territórios e das práticas geradoras de autonomia nos referidos territórios.

Os artigos selecionados pela comissão editorial atendem à diversidade regional do país e denotam produções fruto de cooperação inter-regional, o que corrobora a necessidade de produções locais em sintonia com temas que abrangem a todo o território nacional. Exemplo disso são os artigos produzidos em parcerias Rondônia/Rio Grande do Sul; Alagoas/ São Paulo; Roraima/Rio de Janeiro e Piauí/Ceará/Rio Grande do Norte/Paraíba. Essas parcerias além de representativa das redes de relações entre diferentes núcleos e pesquisadores/pesquisadoras denota os esforços colaborativos na construção de novos saberes, especificamente relevantes para seus contextos e respaldados por discussões e marcos referenciais compartilhados em maior amplitude territorial.

As temáticas desenvolvidas ilustram também algo dessas trajetórias de sensibilização. Não é surpreendente, por exemplo, que boa parte dos artigos submetidos à avaliação para este número estava vinculado a políticas de saúde e à rede socioassistencial. A área da saúde foi das que primeiro articulou políticas de ação específicas a povos tradicionais que implicaram a Psicologia enquanto categoria profissional no Brasil. Por conseguinte, o campo da saúde também tem se configurado como um dos interesses temáticos centrais no campo acadêmico, particularmente em relação a povos indígenas e comunidades quilombolas. Os artigos que abrem esse número, são um exemplo dessa articulação. O artigo "Onde e como se Suicidam os Guarani Kaiowá em Mato Grosso do Sul: Confinamento Jejuiy e Tekoa", de autoria de Pamela Staliano, Marcos Leandro Mondardo e Roberto Chaparro Lopes (Universidade Federal da Grande Dourados - UFGD), além de discutir o campo da saúde mental e, especificamente do suicídio - discute como a mídia apresenta esses casos e sua articulação com o território tradicional dessas comunidades e com as violências exógenas por elas sofridas. Já no artigo de Eraldo Carlos Batista (Universidade Federal de Rondônia - UNIR) e Kátia Bones Rocha (Pontifícia Universidade Católica do Rio Grande do Sul - PUCRS), o foco na análise é em comunidades quilombolas. Em "Sentidos e Práticas em Saúde Mental em Comuni- dades Quilombolas no Estado de Rondônia", os autores discutem repertórios interpretativos sobre saúde mental entres comunidades quilombolas da fronteira com a Bolívia, como: construção do sofrimento mental: reconhecimento e formas de lidar com os sintomas psiquiátricos; recursos utilizados pelos moradores da comunidade no cuidado em saúde mental; e consumo excessivo de bebidas alcoólicas como problema de saúde mental. Esses elementos discursivos da comunidade endossam a necessidade de construção e implementação de intervenções e de saúde dirigidas especificamente para essa população em sua relação com a saúde mental.

Já no artigo "Itinerários Terapêuticos e Formas de Cuidado em um Quilombo do Agreste Alagoano", Saulo Luders Fernandes (UFAL) e Alessandro de Oliveira dos Santos (Universidade de São Paulo - USP) analisam a relação que membros de uma comunidade quilombola do interior alagoano estabelecem com a unidade de saúde de seu território. Nas entrevistas domiciliares, os autores identificam três trajetórias de cuidado presentes no território, definidas como: Automedicação e religiosidade como alternativas à saúde; Chás, ervas e conhecimentos populares como prática de cuidado; Entre a atenção básica, práticas privatistas e benzimentos. Essas estratégias se associam de forma não excludente, mas de maneira hierárquica, demonstrando como os saberes e práticas tradicionais são integrados nas estratégias de cuidado comunitário.

Outro eixo temático relevante, que também ilustra como a Psicologia têm abordado teoricamente o campo da diversidade etnocultural dos povos e comunidades tradicionais pode ser descrito como subjetividades e concepções de pessoa. Esse eixo também ilustra a diversidade de coletivos e comunidades que figuram nesta edição, pois apresenta artigos de pesquisas com grupos de povos indígenas, comunidades quilombolas e com o povo cigano de etnia calon. João Maurício Farias e Inês Hennigen (Universidade Federal do Rio Grande do Sul - UFRGS), em seu trabalho "A Tekoá Ka'aguy Porã como Espaço Ancestral para a Efetuação do Modo de Produção de Subjetividade, o Tekó, Mbya-Guarani”, discutem processos de subjetivação, produção de composições e estratégias de enfrentamento/resistência em meio ao movimento dos indígenas Myba-Guarani de retomada de um de seus territórios tradicionais usurpados, no interior do Rio Grande do Sul. A partir da análise de diferentes materiais e 
ferramentas de comunicação, destacam, em uma perspectiva cartográfica o espaço sociocosmológico Mbya que se atualizou naquela região - a tekoá Ka'aguy Porã - entendendo-o como espaço ancestral (reincorporado ao léxico no movimento de retomada) para a efetuação do modo de vida - o tekó - Mbya-Guarani.

Em "Infância Calin: Socialização Étnica e Identidade Social entre Crianças Ciganas", por sua vez, Grace Kelle de Andrade Cardoso e Mariana Bonomo (Universidade Federal do Espírito Santo - UFES) ressignificam, através da análise etnocultural, elementos tradicionais do campo da Psicologia do desenvolvimento. A partir dos conceitos de socialização étnica e de identidade social, analisou-se o universo psicossocial da infância calin entre crianças ciganas de etnia calon no estado do Espírito Santo. Explorando os universos da lei cigana, tradições do grupo e vivências cotidianas, bem como técnicas de desenho a fim de conhecer as imagens de si, da família e de futuro, as crianças destacam em suas narrativas a vivência da lei cigana e das tradições por meio do uso de vestimentas típicas e da língua caló, moradia em tendas e obediência às normas para o matrimônio, bem como relatam rotinas envolvendo brincadeiras, escolarização e atividades de mediação para o universo adulto. Nesse contexto, manifestam-se movimentos de resistência do grupo, em que a nova geração teria como tarefa manter os elementos identitários essenciais da cultura cigana e criar recursos para manutenção de sua sociabilidade em trânsito nas fronteiras com o mundo não cigano.

Também na interface entre processos evolutivos e etnoculturais, o trabalho de Elisângela Domingues Severo Lopes, Cassiane de Freitas Paixão e Daniela Barsotti Santos (FURG), entitulado "'Os Cansaços e Golpes da Vida': Os Sentidos do Envelhecimento e Demandas em Saúde entre Idosos do Quilombo Rincão do Couro, Rio Grande do Sul", trata de uma pesquisa qualitativa focada nos sentidos sobre o envelhecimento que são produzidos nas narrativas de idosos desta comunidade e identificar ações e estratégias usadas por eles na promoção da saúde no local. A análise por meio da elaboração de árvores de associação de ideias gerou dois eixos temáticos: 1 . Os sentidos do envelhecimento: a idade cronológica, a solidão, os acontecimentos da vida, a perda das funções do corpo e o adoecimento; 2. Práticas para a obtenção da saúde: cuidados com a saúde por meio do comparecimento às consultas médicas, realização do tratamento pres- crito e medicação; ações de promoção de saúde que envolvem alimentação, caminhadas e atividades do cotidiano que são praticadas no decorrer de sua história. Os resultados enfatizam a necessidade de uma Unidade Básica Saúde da Família Quilombola local, e a necessidade de se desenvolver trabalhos e pesquisas da Psicologia em comunidades tradicionais.

O terceiro eixo de artigos, talvez possa ser caracterizado pela sua ênfase na participação política, muito focadas na implicação territorial, mas também destacando elementos de geração e etnicidade. O texto "Peles e Vidas Transformadas em Asfalto: Inquirições Ético-Políticas de uma Barbárie”, de autoria de Lázaro Batista, Leonardo Evangelista de Nardin (Universidade Federal de Roraima - UFRR) e Luís Antônio Baptista (Universidade Federal Fluminense - UFF) aponta algumas passagens e relações entre a ditadura civil-militar brasileira e a constituição do estado de Roraima, destacando o incremento de fluxos migratórios, à extração predatória, à censura contra pessoas e, especialmente, ao contato genocida do homem branco com indígenas yanomami e Wamiri-Atroari na construção de duas estradas federais que atravessam os territórios dessas comunidades tradicionais. Do ponto de vista teórico-epistemológico, busca-se, com a Psicologia e suas diferentes interlocuções, um esforço aproximativo com tais histórias, as formas de contá-las e as diferentes políticas que podem sustentar nossa escuta do narrado.

A produção de Juliana Cabral de Oliveira Dutra e Claudia Mayorga (Universidade Federal de Minas Gerais - UFMG), intitulada "Mulheres Indígenas em Movimentos: Possíveis Articulações entre Gênero e Política" destaca, a partir de uma aproximação posicionada com determinados movimentos indígenas e com mulheres lideranças indígenas no Brasil, a emergência, no cenário macropolítico do país, do sujeito político mulheres indígenas e sobre as possíveis aproximações de suas pautas com as pautas feministas, em especial, o feminismo pós-colonial.

Outro grupo importante de trabalhos, enfatizou o que se pode definir como produção do conhecimento e atuação profissional da Psicologia. Dentre os textos que organizam esse eixo, figura a análise "A Psicologia no Contexto das Comunidades Tradicionais: da Emergência Étnica à Perspectiva Ético-Estético-Política", na qual Antônio Vladimir Félix-Silva (Universidade Federal do Piauí - UFPI), Gabriela Pinheiro Soares (Fundação Gregório Baremblitt e Instituto Félix Guat- 
tari), Ana Caroline dos Santos (Centro de Referência Especializado de Assistência Social - CREAS Itarema/ $\mathrm{CE}$, Lara Mendes Braga Rigoti (Universidade Potiguar) e Maria Valquiria Nogueira do Nascimento (Universidade Federal de Campina Grande - UFCG). Neste trabalho, discutem a produção de subjetividade de mulheres da Comunidade Quilombola de Macambira de forma integrada à produção de subjetividade de psicólogas pesquisadoras, valendo-se do método cartográfico, com visitas às casas das mulheres e à comunidade quilombola. A análise dos processos de subjetivação das mulheres quilombolas está marcada pela sororidade e interseccionalidade, singularizações e reproduções de relações de saber e poder vigentes, que também atravessam os processos de subjetivação das psicólogas pesquisadoras.

No trabalho "Temporalidade e Corpo numa Proposta de Formação do Psicólogo para o Trabalho com Povos Indígenas", de autoria de Danilo Silva Guimarães, Dario Marinho de Lima Neto, Larissa Moreira Soares, Pamela Damilano dos Santos e Thiago Schaffer Carvalho (USP), discutem as práticas do serviço Rede de Atenção à Pessoa Indígena - vinculado ao Departamento de Psicologia Experimental do Instituto de Psicologia da Universidade de São Paulo - enfatizando os impactos de mudanças nos procedimentos de visitas às comunidades para a formação do psicólogo. A exposição do corpo do psicólogo em formação a contextos ritualizados segundo padrões distintos de sua cultura de origem faz emergir inquietações e angústias que caracterizam o modo de relação com a alteridade.

Finalizando nossa edição, o texto de Abrahão de Oliveira Santos (UFF), "O Enegrecimento da Psicologia: Indicações para a Formação Profissional”, ten- siona a possibilidade de pensar o diálogo entre a Psicologia e as práticas de cuidar na espiritualidade de matriz africana, trazendo, no contexto da resistência negra, os valores que se apresentam nos saberes dos terreiros, acolhimento, comunidade, ancestralidade, e o lugar desses saberes ao longo da história da resistência negra no Brasil. O propósito do texto é indicar a importância das psicólogas e dos psicólogos entrarem em contato com alguns conhecimentos das tradições e saberes não ocidentais, presentes numa parte significativa da população brasileira. A perspectiva apresentada pelos saberes da população de terreiro e sua conexão com as lutas históricas do povo negro, poderiam compor na atuação, junto à população brasileira, das psicólogas e dos psicólogos. É aí que faz sentido o reclame ao enegrecimento da Psicologia.

Por fim, agradecemos a colaboração de todos os autores e autoras, assim como muitos e muitas que também submeteram suas propostas de texto mesmo que, infelizmente, não tenhamos podido contemplar a todos escritos. A chamada especial da revista Psicologia: Ciência e Profissão também serviu para que possamos conhecer a diversidade de mobilizações teóricas, acadêmicas e especialmente práticas de psicólogos e psicólogas e todo o Brasil, tentando construir uma Psicologia mais diversa, abrangente e conectada com segmentos perseguidos e atacados de nossa sociedade. Os povos tradicionais vivem há mais de cinco séculos sob o jugo do colonialismo com muita luta e resistência pela sobrevivência e pela dignidade. Que bom que a Psicologia brasileira se soma a essa batalha.

Uma boa leitura.

Os editores

\section{Referências}

Conselho Federal de Psicologia. (2013). Referências técnicas para atuação das(os) psicólogas(os) em questões relativas a terra. Brasília, DF: o autor.

Conselho Federal de Psicologia. (2006). Seminário Nacional A questão da terra: Desafios para a Psicologia. Brasília, DF: o autor.

Conselho Regional de Psicologia da 6a Região - CRP-6. (2010). Psicologia e povos indígenas. São Paulo, SP: o autor.

Conselho Regional de Psicologia da 6a Região - CRP-6. (2016). Povos indígenas e psicologia: A procura do bem-viver. São Paulo, SP: o autor.

Groot, S., Hodgetts, D., Nikora, L. W., \& Leggat-Cook, C. (2011) A Maori homeless woman. Ethnography, 12(3): 375397. https://doi.org/10.1177/1466138110393794

Hwang, K. (2017). The rise of indigenous psychologies: In response to Jahoda's criticism. Culture \& Psychology, 23(4), 551-565. https://doi.org/10.1177/1354067X16680338 
Li, W. W., Hodgetts, D., \& Foo, K. H. (2019) Asia-Pacific perspectives on intercultural psychology. London: Routledge.

Teo, T. (2011). Empirical race psychology and the hermeneutics of epistemological violence. Human Studies, 34(3), 237-255. https://doi.org/10.1007/s10746-011-9179-8

\section{Adolfo Pizzinato}

Professor do Programa de Pós-Graduação em Psicologia do Instituto de Psicologia da Universidade Federal do Rio Grande do Sul (UFRGS), Porto Alegre - RS. Brasil.

(D) http://orcid.org/0000-0002-1777-5860

\section{Danilo Silva Guimarães}

Professor do Programa de Pós-Graduação em Psicologia Experimental do Instituto de Psicologia da Universidade de São Paulo (USP), São Paulo - SP. Brasil.

(D) http://orcid.org/0000-0002-0583-2979

\section{Jáder Ferreira Leite}

Professor do Programa de Pós-Graduação em Psicologia do Departamento de Psicologia da Universidade Federal do Rio Grande do Norte (UFRN), Natal - RN, Brasil.

(iD) http://orcid.org/0000-0002-6045-531X

Como citar: Pizzinato, A., Guimarães, D. S., \& Leite, J. F. (2019). Psicologia, povos e comunidades tradicionais e diversidade etnocultural. Psicologia: Ciência e Profissão, 39(n.spe), 3-8. https://doi.org/10.1590/1982-3703000032019

How to cite: Pizzinato, A., Guimarães, D. S., \& Leite, J. F. (2019). Psychology, people and traditional communities and ethnocultural diversity. Psicologia: Ciência e Profissão, 39(n.spe), 3-8. https://doi.org/10.1590/1982-3703000032019

Cómo citar: Pizzinato, A., Guimarães, D. S., \& Leite, J. F. (2019). Psicología, pueblos y comunidades tradicionales y diversidad etnocultural. Psicologia: Ciência e Profissão, 39(n.spe), 3-8. https://doi.org/10.1590/1982-3703000032019 